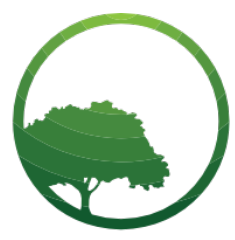

Business \& Social Science IJRBS

\section{Research in Business and Social Science}

IJRBS Vol 8 No 4, ISSN: 2147-4478

Contents available at www.ssbfnet.com/ojs

\title{
Design Thinking as a Catalyst for Technology Start-Ups
}

\section{Ozan Soyupak}

Corresponding Author: Istanbul Teknik Universitesi, Mimarlik Fakultesi, Endustri Urunleri Tasarimi Bolumu, Istanbul, Turkiye.

ORCID ID: 0000-0003-4316-1712

\section{Humanur Bagli}

Istanbul Sehir Universitesi, Mimarlik ve Tasarım Fakultesi, Endustriyel Tasarim Bolumu, Istanbul, Turkiye.

\begin{abstract}
This study is based on the projects held in a Design Thinking Graduate class in 2016-2017 and 20172018 Fall Semesters, in an ITU industrial design department. Based on the hypothesis that design thinking interventions to entrepreneurship projects will help their development, graduate students were paired with technology start-ups. The aim of the project is to intervene the project development process of technology start-ups with a human centred perspective by the help of the tools of design thinking approach, develop ideas for solving existing problems, also pin out new problems that are not classified as problems by the companies yet. Following this idea, students were required to design and conduct their own process by the help of design thinking approach and related methods. The number of the projects held during the process was 34 and 4 of them will be explained in detail in this paper. This study is significant in terms of investigating how design thinking affects start-up culture as a catalyst, in which phase/s of the projects design thinking is more relevant and effective, how design thinking helps find solutions to missing and premature aspects of entrepreneurship projects.
\end{abstract}

Key words: Design Thinking, Technology Start-ups, Entrepreneurship

JEL classification: $A 12$

Submitted: 12.06.2019 - Accepted: 28.06.2019

\section{Introduction}

Today startups present a new way of organization and business manner apart from large scale firms and SMEs. Startups, which have important structural differences from other type of organizations, can be defined as temporary organizations that are innovation centered, scalable, repeatable and searching for profiting business model and they usually have business models related with technology. Concepts of startups and startup ecosystem are involved in contemporary agenda of public policies, private sector, universities, etc. 
both in global level and national level such as in Turkey. Although there is an instinctive aspect of being an entrepreneur, as Tarekegne \& Gelaneh (2019) suggested that some qualities of entrepreneurship should be taught in order to strenghten the required skills and to make the enterprise sustain. Startups should have skills in different disciplines such as management, engineering, design, etc.. Within this perspective, in this study, interaction between industrial design discipline and startups is discussed via design thinking interventions made in the context of Design Thinking course of Industrial Design Master Degree Program of Istanbul Technical University (ITU). Within the most up-to-date definition, industrial design is a problem solving process which directs innovation, creates business success and helps increasing the quality of life by innovative products, systems, services and experiences. Within time, the definition of the industrial design has been updated to include designing beyond the physical product (systems, services, experiences, businesses) and innovation. Today, methodology of the designer in problem solving is used by different disciplines. Beginning with empathy, involving divergent and convergent phases, getting knowledge from user, and making user involved in the process are the main properties of the methodology. Similar approaches to the design methodology can be seen in business and entrepreneurship literature. Glen and others (2015) emphasizes that design thinking can contribute to insufficiencies of business schools' analytical thinking methods. Within this regard, in this study, contribution of industrial design discipline to startup's processes is discussed within the design thinking perspective. This study is based on the projects held in a Design Thinking Graduate class in 2016-2017 and 2017-2018 Fall Semesters, in Department of Industrial Design. Based on the hypothesis that design thinking interventions on the process of entrepreneurship projects will help their development, graduate students were paired with entrepreneurs in ITU Seed Incubation Center which are supported by The Scientific and Technological Research Council of Turkey (TUBITAK) Individual Young Enterprise (BIGG) Support Program and then an intervention process for fifteen weeks was started. Students were required to design and conduct their own process by the help of design thinking approach and related methods. Students share their ideas about the process and the companies they are working with each week with the rest of the class and instructors and most of the ideas were developed collectively. The process was completed with an open meeting attended by all stakeholders and feedbacks were asked and collected from all parties of the project.

Main aim of the study is to reveal the structure of cooperations and interactions between industrial design education and startups and evaluate the potential contributions of this interactions and cooperations to every stakeholder. In this study, to frame the relation between design thinking and entrepreneurship, at first; design thinking, innovation, design education and entrepreneurship concepts will be examined. After sharing structure of the research and sample design interventions to startups, affect of design thinking interventions will be discussed within the perspective of every stakeholder.

\section{Literature Review}

\section{Design Thinking and Innovation}

Design Thinking (DT) is the way to find solutions to difficult problems in a human-centered way; it consists of collaborative, team-based and interdisciplinary processes (Curedale 2013). Beckman ve Barry (2007) defines design thinking as learning process of observesion, framing, ideation and solution development. Design thinking is a discipline that uses the designer's sensibility and methods to match people's needs with what is technologically feasible and what a viable business strategy can convert into customer value and market opportunity (Brown 2008). Müller and Thoring (2012) stated that design thinking process usually does not start with an idea, but with a problem or a question, instead. Ideas are generated in the process, but before that there is an extensive research phase. All these methods give way to more innovative solutions to a various kinds of different problems sets, whether they are directly related with design in its classical sense or not. As the subject of the study is based on the start-up ecosystem and its interconnections with design and design thinking, innovation becomes the key term in this context. Drucker (1985) describes the base of entrepreneurship as systematic innovation practice and mentions that most of the innovations are results of a conscious and systematic search of innovation. Innovation in the literature is defined as applicable proposals which create value for user and supplier and which are new for a specific period of time and concept (Kumar, 2013). If a creative idea is commercialized and increases productivity, it is counted as 
innovation and what is expected from an innovation is providing benefit to any area it is used (Sabuncu, 2014). According to Kelley and Littman (2005), in business world, which has always place for innovation, listening customers is helpful but does not contain values for estimating the future. Instead of asking direct questions to the users, path of the revolutionary innovations can be enlightened by applying observation methods such as spending a day with them (Kelley and Littman, 2005). Design thinking is seen as a powerful way of thinking and mind set to reach the innovation. It finds a place in business world and educational programmes for adopting innovative thinking approach to people.

\section{Design Thinking in Academic Educational Programmes}

One of the areas in which design thinking finds itself a place is academic educational programmes. According to Melles et al. (2012) recently design thinking is introduced to students in non-design related disciplines like business and management schools as a tool in decision making in other fields. When it comes to design thinking in design schools, it is focused on thinking beyond the output of product, on modelling the work, system or service and design students are expected to apply their design thinking abilities to non-design related problems. It finds itself a special place and flourished in different departments of many schools such as Stanford D.School, HPI, MIT, University of Virginia, London Business School etc.

For the last two years in the department which this research was realized, courses focusing on design thinking added to syllabus. In 2016-2017 Fall Semester, this project was implemented within the scope of one of these courses; "Design Thinking" Master Course.

\section{New Enterprises and Ecosystem of Entrepreneurship}

The rise of the culture of entrepreneurship in start-ups begins with the differences between small scale and big companies. At first, start-ups were seen as the smaller version of big companies and on this basis MBA ideas applied to big companies were also applied to start-ups. However, this strategy caused some problems and so it has been understood that start-ups differ from the big companies in terms of their flexibility levels and context (Blank and Dorf, 2012). So, the business world, also with the help of advances in technology, has led to the rise of a novel company types named as start-ups. Ergen (2014) in the most general definition of the term, defines the entrepreneur as the one who gets risk. At fuzzy environment of the first phases of a new enterprise, risks should be ordered according to their priorities, and then they should be tried to get decreased by designing experiments to solve them; because risk and value are inversely correlated (Gilbert and Eyring, 2015). Entrepreneurs pass the fog of obscurity by testing their hypothesis, by making "mistakes" (Hoffman and Casnocha, 2012). Practice based knowledge is worthier than planning and thinking and it can only be won by making for the entrepreneur. The new tech-based enterprises, start-ups, became attractive for investors and stakeholders like public services etc. because they easily reach high volumes and these new entrepreneurs are different than conventional ones. Newness and new product development are very important in public policies in Turkey. By the help of TUBITAK BIGG Fund Support Program, technology and innovation based entrepreneurs are supported by government. The aim is to have entrepreneurs that have added value with a potential of qualitative employment (Tubitak 2017). By the help of these new entrepreneurship projects, economic growth and international competitiveness are sought to reach. All new enterprises mentioned in this research are supported by this governmental support program.

Management scholars first showed an interest in links between business and design in the mid-1980s, followed by scholars in other areas (Johansson-Sköldberg et al., 2013). The designer's approach to the problem and solving methods of it attracted the attention of other disciplines that created a will to adapt and use this approach. This research can be seen as a continuation of this trend in design education context.

\section{Research and Methodology}

\section{Perspective of the Researchers}

The Executives of this study have undergraduate and graduate degree on industrial design and work as instructors in Department of Industrial Design. For that reason, they are experienced in teaching in more practice based approaches and methods. In general, most of the projects given in industrial design education 
are focused on physical output of the product and run individually by students. In this project, with a more progressive and critical approach, researchers have tried to transfer their ideas on how design thinking cannot be restricted to reach only a physical output and also how solving the problem in a group work becomes more productive than handling it individually. In that sense, researchers' leading focus on group work resembles with the concepts of entrepreneurship, because entrepreneurship is a team play rather than an individual act (Ergen, 2014). Handling start-up projects with this approach as design problems by participation of all of the students using the class environment has created a context that supports this culture.

\section{Process of the Study}

In 2016-2017 fall semester 19 students and 2017-2018 fall semester 17 students enrolled the design thinking course and joined this study. In first study majority of the students had industrial design undergraduate degree and continue to graduate programme of industrial design. Also, there were some students enrolled the course with different undergraduate disciplines such as architecture, interior architecture, dentistry, mechanical engineering and shipbuilding engineering. In second study which was implemented in 2017-2018 fall semester majority of graduate students had undergraduate degree in engineering disciplines especially in computer sciences. Also, there were students who had undergraduate degree in business, shipbuilding engineering and industrial design. Terms were summarized visually in Figure 1. At the first two weeks of the 15 weeks terms, theoretical knowledge in design thinking has been shared with students; however in other weeks, more suitable to the nature of the approach, practical studies in the field were emphasized and encouraged. Another reason of having only 2 weeks for theoretical explanation was most of the students' familiarity with the subject of design thinking.

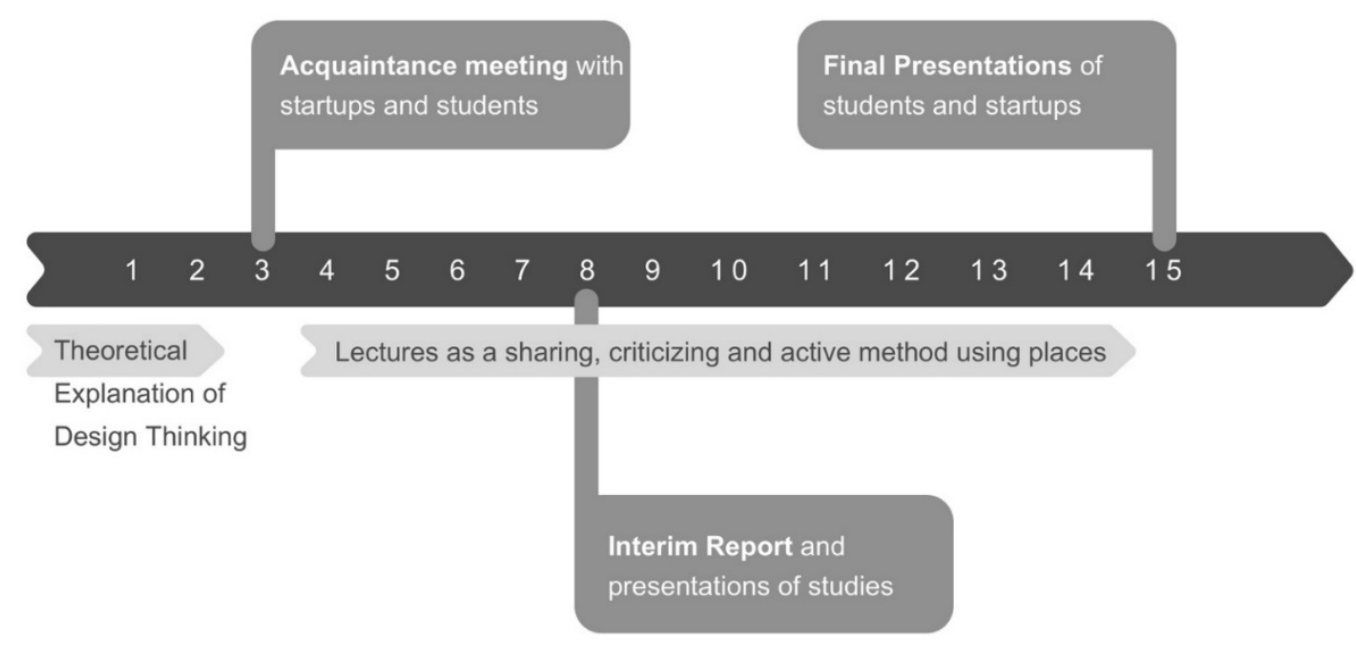

Figure 1: Weekly summary of terms

Also at the beginning of the processes meetings were organised to introduce stakeholders, students and start-ups to each other and to clarify the process. The presentations on design thinking and start-ups were made by the course instructor and goals and aims of the study were explained. Thus, possible misunderstandings for start-ups were tried to be prevented. The aim of the project was explained briefly as "to intervene the process of entrepreneurs as a catalyst with a human centered perspective by the help of the tools of design thinking approach, develop ideas for solving existing problems, also pin out new problems that are not classified as problems by the companies yet." It was especially emphasized that, the aim of the project was not to provide a product or graphic design service support, because the majority of the group was graduate of design.

In the part at which everybody introduces him/herself, hypothesis of researchers about the necessity of design thinking interventions on the process of entrepreneurship projects once again was proved to be right. In 2016-2017 fall term, one of the speakers in the meeting was iTÜ Arı Teknokent Business Development \& Corporate Communication Manager of the technopolis. She worked with new entrepreneurs in incubation period, mentioned the common mistakes of the entrepreneurs and how design thinking could help on 
preventing them. She emphasized how design thinking is more related with the practice rather than with thinking and stated that she never come across an enterprise idea that is not related with design, directly or indirectly. Another problem that she mentioned about new enterprises was their being disconnected with the market and target users. She exemplified this with a story of an enterprise in ITÜ Seed Incubation Center. It was a company which developed a project for kindergartens but she noticed that they never made a field research and used observation for solving this problem. After the meetings of both parties, graduate students and entrepreneurs were paired randomly, regardless of students' expertise or being eager to the new enterprise's work and areas of interests. The reason for this is researches of this project think that facilitation in design thinking process is not based on expertise in some specialized subjects, but more on methods tailor-made for different cases. This idea can also be supported with this connection: According to some social scientists, specializing in a field make it difficult in creating innovative ideas (Michalko, 2006). So, design thinking is closer to an approach focusing methodological view and process management skills than specializing on a field. Students were asked to prepare a project report in the middle of the term, in addition to their final presentation and report at the end of the semester. Content of the report was shared and this content did not involve definite topic and definitions; instead, it was defined as a general framework on how to handle the issue. Students shared current situation of their research with the class every Thursday morning and got critiques not only from instructors but also from their friends. During the semester, students both made field work with their paired enterprise and collective study by criticizing other student's work in lectures. In addition to that, some of the course hours were used to apply an active method for students' work; structured and semi structured applications like focus group interview, brainstorming, etc. were realized in the class sessions.

At the end of the semester, course studies and outputs were shared with an open to public meeting. Entrepreneurs and students shared their process and reflections about its impact on themselves in their presentations. Especially active participation of the entrepreneurs in presentations and their feedbacks, made the organization more valuable. During these processes different methods were used for collecting data from the students' (Figure 2). So researchers had a chance to follow and observe students' and start-ups' processes throughout the semester. At the end of the 15 weeks feedbacks were taken from both students and start-ups. Also, in 2017-2018 fall term a blog was opened for collecting data as instant as possible. Students have shared their studies week by week in detail via blog entries and also they have commented others' studies.

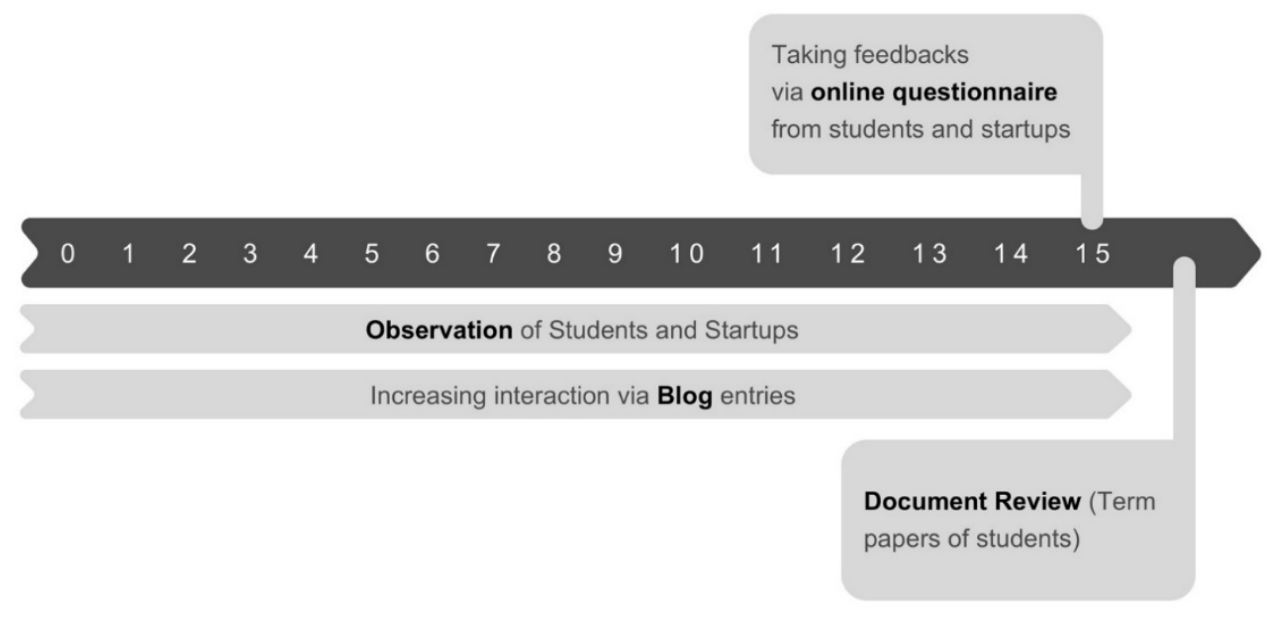

Figure 2: Chronological summary of data collecting methods

\section{Intervention to new enterprises with design thinking: 4 sample cases}

The specialized subjects of the entrepreneurs were various; from software to hardware, from b2c (business to customer) to b2b (business to business). In the upcoming chapter, among 34 study, 4 illustrative and most successful cases will be shared in detail. First two of the cases were conducted in 2016-2017 fall term and second two of them were conducted in 2017-2018 fall term. 


\section{Enterprise A}

First enterprise, established in 2015 with TUBITAK funding, develops a home use blood thinner device used to measure patients' blood coagulation time. The enterprise consists of two entrepreneurs who work also as fulltime engineers in different jobs. Before the intervention phase, the enterprise listed their weaknesses; first, financial problems, second, lack of communication with potential users and third, design and brand management problems. The student, aiming to intervene to the enterprise by design thinking, has focused mostly on second and third problems. After the study, possible product developments which can be done and expectations of specialists/doctors from point of care testing (POCT) devices have been defined.

Three different methods / approaches were summarized below.

Interviews with doctors/specialists: 6 interviews were made and 3 questions were asked. Results of the interviews are evaluated with response analysis method by determining 10 words.

Focus group work, with graduate level industrial design students to measure POCT device perception: 13 students were asked to criticize 10 POCT diabetes devices according to various criteria (Figure 3).

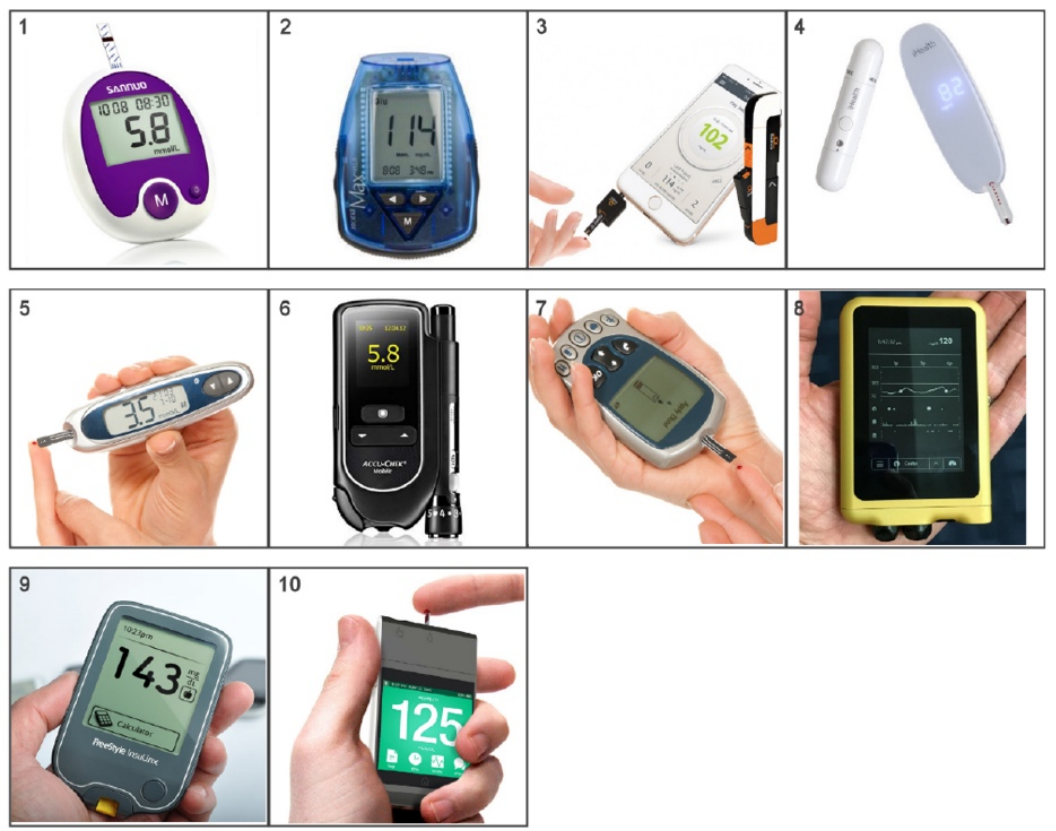

Figure 3: Visuals of the 10 POCT devices using focus group work

A work for measuring perception of diabetic people on POCT devices by using semantic differential method (Osgood et al., 1957): With the help of the keywords from second work, it was made by diabetic people and their relatives via online communication. After these studies, student has reached to some keywords related with form and function which can be used in design process of the product and shared these criteria to constitute a design vision with enterprise. He made some inferences about the effects of form and material decisions of medical devices on basic needs such as "trust". In the final presentation, the entrepreneur who he worked with has mentioned that their focus was more on technology, sensors and product development process, however, with the help of the gathered data in this study, they decided to develop a second prototype that they will strengthen the relation between target user and product. Another thing is that the student in this project was not a designer, but a dentist with a PhD. He reflected about this project in a very interesting and interdisciplinary perspective. He said:

"In this process, I understood how I can link design with my job. I can describe design thinking as the 'doctor of design process'. Just like when a patient consults you, he explains his problems and you as a doctor, evaluate the problems by applying some methods. It is like giving the right medicine. You are trying to create a solution." 
A comment from a non-design related discipline adds value and a brand new perspective to design thinking in an interdisciplinary point of view. This made us rethink about the prejudice on design thinking whether it is better to be implemented by the people from the design related disciplines or not.

\section{Enterprise B}

The product of the second enterprise is a mobile application which is developed by the entrepreneur to solve a problem derived from his daily life. It depends on an experience that memory recording habit is preventing living the moment in different circumstances, he aims to develop a solution which makes the steps of the process of recording the moment easier. So, he focuses on some problems like recording the memories numerically, gathering this data to form a composition and sharing them with others. Intervention of the student has begun with a user centred process by using design thinking approach. After the interview with the entrepreneur, student has defined two goals; simplifying problem definition and detailing the user needs. Methods used by student according to determined goals can be divided as data collection and data analysis (Figure 4).

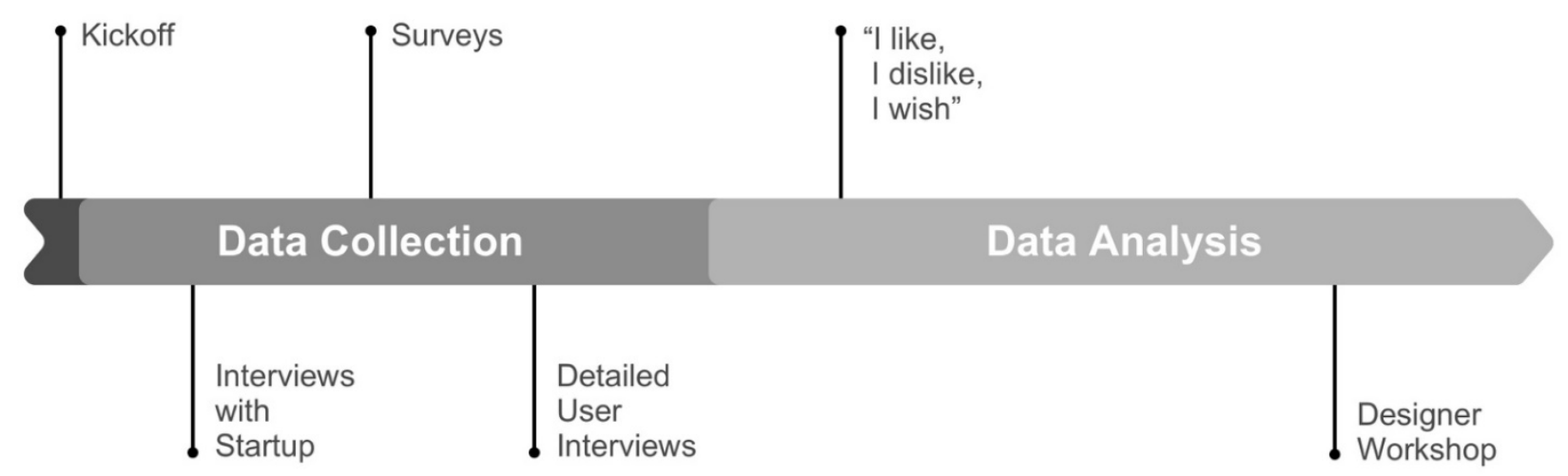

Figure 4: Methods using the process of Enterprise B

Works done under data collection is summarized below.

Survey: Before the detailed interviews, she collected info about social media and travelling habits of the potential users.

Detailed user interviews: Detailed information about social media and travelling habits of the potential users and the reasons of them has been learned. During interviews, users also shared screenshots of their smartphones' home screen and by so she suggested a new method which is very suitable for her case, named "What is in your home screen?" (Figure 5).
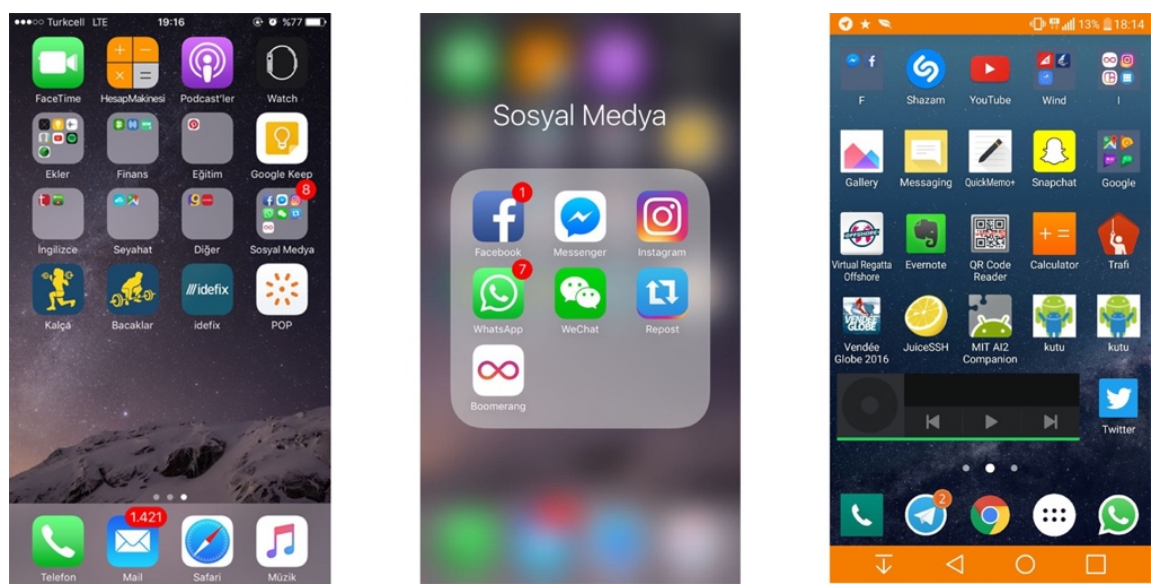

Figure 5: Sample screenshots from participants' home screen 
Methods used under data analysis process are below:

"I like, I dislike, I wish" Chart: User interviews have been re-listened, written and statements have been grouped into 3 topics.

Designer workshop: A group of professional designers answered the question "If you are to design a mobile app for social media, what would be its properties?". Student reached different alternatives to strengthen user and product relation.

In this process, detailed information about potential user of the product is gathered and alternative ways to use these data on product development are offered. Entrepreneur, in final presentation, at which output of the study is discussed, has defined the place of their user research as:

"We can sometimes be prejudiced in user research. As enterprises, we don't have enough sources to invest on this issue. Since the process is not clear, even if we try to get a service for it we cannot even define what we are looking for clearly."

As can be understood from this statement, the entrepreneur has learned that he should pay attention to user without prejudice by the help of design thinking. He develops a vision on habits of the users and how to apply this to new product or new application. A surprising example among findings of the study that gave a vision to the entrepreneur is users' concern about application's battery consumption. Such criteria did not appear on prior research which didn't focus on user centred approaches.

\section{Enterprise C}

Third enterprise is a food tech start-up working on functional herbal caviar by ionic gelation method. The start-up tried to develop 100\% plant based and functional (i.e., high nutritional) caviar. Team consist of 4 engineers, 2 of them are food engineers, 1 business administrator and 1 designer. The student got involved in the team at the very beginning of the process and this gave him a pivoting chance during his study. At the early stage of the study student focused on the functionality of the potential product than he changed his focus to the vegan and vegetarian market.

Field studies performed in this study are summarized below.

Restaurant visits: The student and the entrepreneur modified some high-end restaurants' existing meals with their herbal caviar for tasting by the chiefs and business managers of restaurants (Figure 6). This is one of the successful prototyping examples. With the help of these prototypes they both introduced their products and took pre-orders.
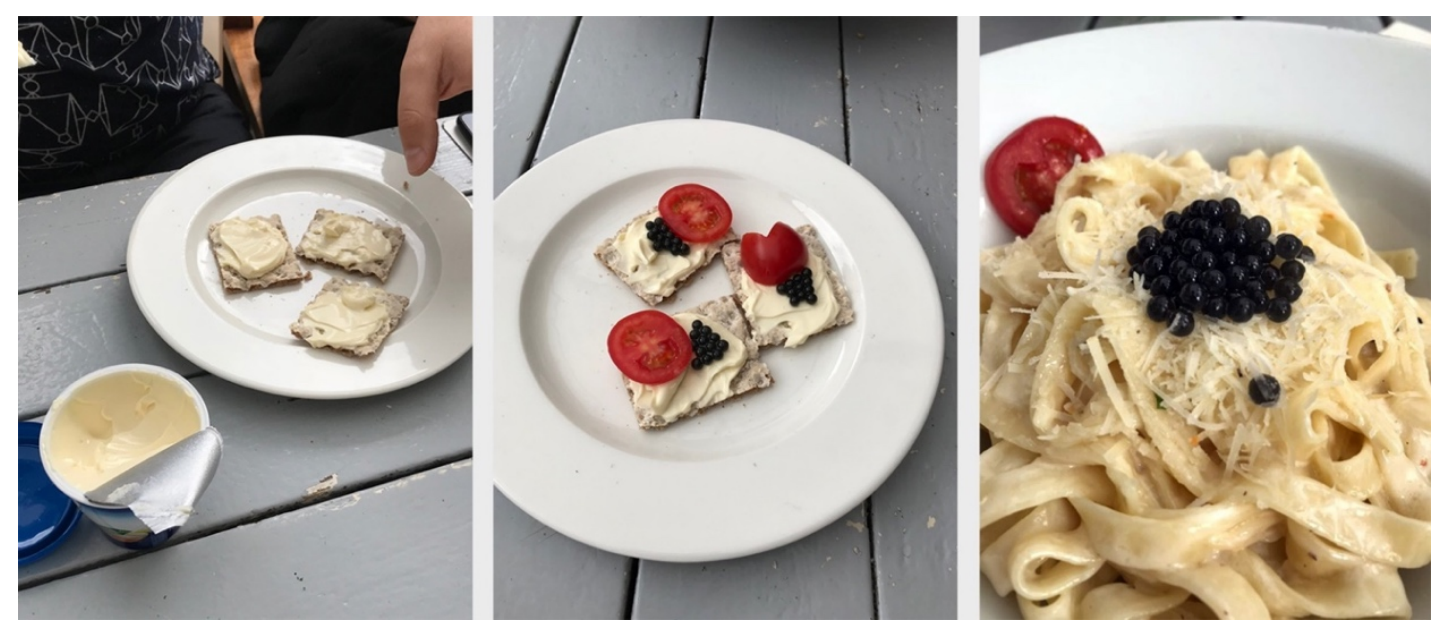

Figure 6: Prototyping during restaurant visits with existing meals

Vegan Restaurant and Market visits: He made semi-structured interviews with owners of the vegan restaurants and markets. He also used card sorting method to learn the customer's perceptions and notions which were needed to be highlighted (Figure 7). 

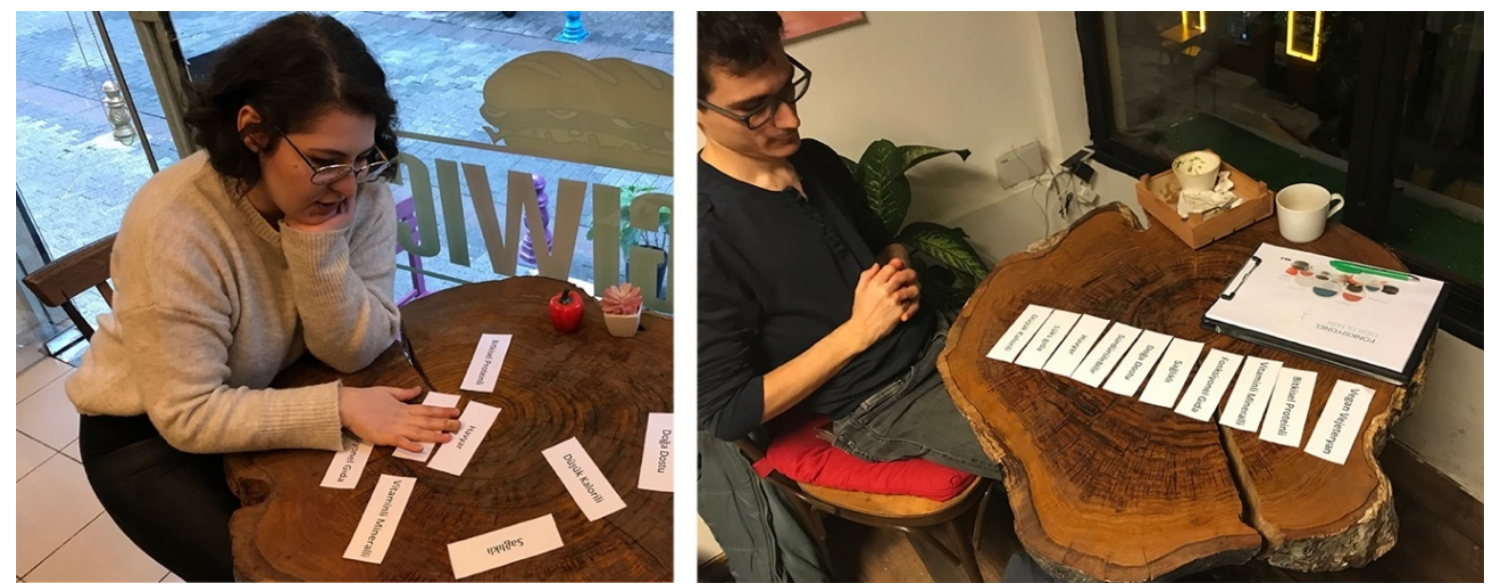

Figure 7: Vegan Restaurant and Market visits

As a result of this study start-up reached the information of the potential users whom they could promote their product. Persona method could have been usable for the next phase of the start-ups to clarify their potential customers.

\section{Enterprise D}

Fourth enterprise is developing a wearable device for Parkinson's disease patients. Their product is a kind of bracelet for data logging and preventing the patients' hand tremors. Founders of the start-ups had engineering background so student decided that start-ups focused on technical problems and device's potential benefits to the doctors. Their potential users, Parkinson's disease patients, were without priority for start-ups at the beginning.

Methods using this study summarized below.

Popular media scan (Kumar 2013): It was made to reach the initial foresight regarding the subject. It can be useful and essential especially this kind of specific topics such as; a type of disease etc.

Ethnographic interview with doctors and patients: Both entrepreneur and student visited Parkinson's disease clinic together and collected detailed data about both potential users' needs (Figure 8).
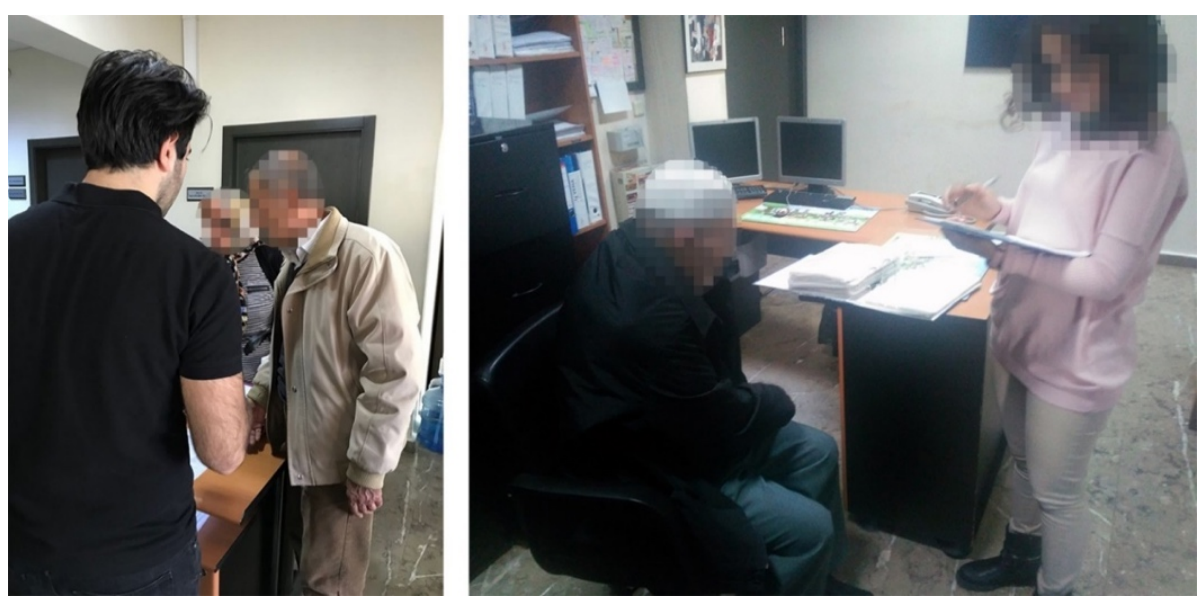

Figure 8: Interview with doctors and patients

Workshop session for analysis: It was made for clustering the data which were collected in previous stages and creating new ideas by the help of these data (Figure 9). 

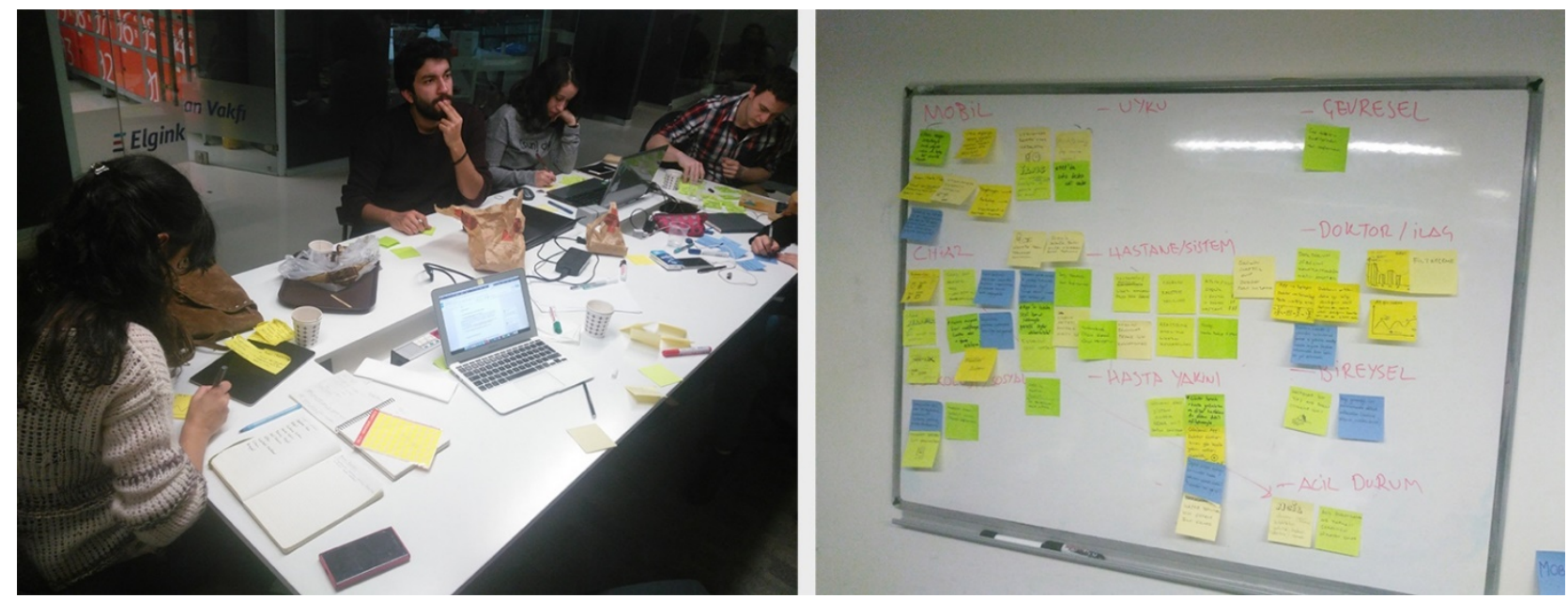

Figure 9: Workshop session for analysis

One of the founder of the start-up compared design thinking and his background with the help of the experience which he gained via this study. According to him, in engineering perspective they are more pessimistic, how it is not made and worst scenarios have priority and it caused the restriction on the perspective of the founder; however this approach created a new and more optimistic perspective for their process. Also, he indicated that focus groups consist of engineers have to be warned to be constructive rather than destructive.

\section{Result and Discussion}

One of the common points of four studies that are mentioned in detail and other studies done within the context of the course is that entrepreneurs have a tendency to focus on their technological development and prototype and they usually miss the actual needs of potential users. At the first phase of the enterprise process, how well the existing solutions fit to problems of target potential user group and what problems are not solved in the market are not usually analysed in detail. Constraints on time, money and human resources of the new enterprises can be an important reason for their not making detailed user and field analysis. Another reason is that, with the engineering reflex as we can call it, they prefer to give priority to develop the technology itself and create technological solutions to certain problems rather than other issues. It is observed that in their previous education program, given by mentors, new entrepreneurs are aware of design thinking in some degree. However, since the previous educations given in the incubation center were made in short durations and mostly theoretical, they could not have a chance to make an application or workshop based on this information. In this study, since the whole process was 15 weeks long, a semester time, it has become more sequential and iterative, as the design thinking method suggests. Based on this experience, we can say that long term design thinking workshops focusing on the processes like this study seem to be more productive and sustainable than popular daily design thinking workshops. Also, because this study was held as a part of a graduate class, quality of the research itself was scrutinised and developed during the semester, whatever the subject matter is. So, the case presented here can be counted as a new approach and a connection with research design in building design thinking as a catalyst in entrepreneurship ecosystem.

Enrolling and intervening students' coming from different disciplines is another property which makes this study valuable and unique. It can be said that some of the students from other disciplines implemented a very successful process compared to design students. In intervention process with design thinking, it was observed that designer's abilities are not required; on the contrary, the reflex to design sometimes carries the process out of its borders which is far from the role of the researcher in design thinking process. To exemplify this, the request of one of the firms from a design based student to develop design ideas, such as a logo and identity design, can be given. One negative aspect of the study is related with the specific phase of the entrepreneurs' project development when the intervention of design thinking happens. For enterprises were mostly in the last phase of their project development, the priority given was mostly on product/prototype 
development. If the intervention happened in previous stages, process would be more productive because the entrepreneurs would have acted more freely and design thinking would contribute on developing new products more. On the other hand, participating this study in an advanced stage gave start-ups the chance to countercheck and verify by reconsidering their previous decisions in the process.

\section{Conclusions}

This study is significant in terms of investigating how design thinking affects start-up culture as a catalyst , in which phase of the projects design thinking is more relevant and effective, how design thinking reveals missing and premature aspects of entrepreneurship projects, also how it can also be held as a promising tool for design education.

This study links the business and entrepreneurship literature to design education. According to gathered data, contributions of long-termed collaboration between industrial design education and startup ecosystem to startups can be summed up as making user centered research and data collection, gaining awareness, developing user-centered perspective and taking design consultancy. Outcomes of this collaboration have a hierarchical relation. At first, entrepreneurs gain awareness about design and design thinking concepts, after that user-centered perspective is developed. By completing these stages, entrepreneurs can run usercentered researches independently and collect related data. In addition to contributions to startups, this study has also served to the development in technical abilities and managements skills of participant industrial design students.

As Boratav (1988) pointed out, national industry of Turkey has been tried to be established by protective policies. In other terms, in Turkey, entrepreneurship and industry has not developed naturally. Within this respect, this study contributes to establishing synthetic relation between design and startups by design education initiative.

To conclude, placement of design thinking in entrepreneurship ecosystem and placement of entrepreneurship in design education and possible other collaborations is worthwhile in terms of development for every stakeholder.

\section{Acknowledgment}

This manuscript was produced from the author's doctoral thesis named as "An Experimental Study on Possible Interactions and Collaborations between Industrial Design Education and Startup Ecosystem" which was carried out under the guidance of Hümanur Bağlı as part of the Industrial Product Design Graduate Program of ITU Graduate School of Science, Engineering and Technology.

\section{References}

Beckman, S. L., \& Barry, M. (2007). Innovation as a learning process: Embedding design thinking. California Management Review, 50(1), 25-56.Retrieved from https://doi.org/10.2307/41166415

Blank, S. G., \& Dorf, B. (2012). The startup owner's manual. the step-by-step guide for building a great company. Pescadero, Calif.: K\&S Ranch, Inc.

Boratav, K. (1988). Türkiye Iiktisat Tarihi 1908-1985. İstanbul: Gerçek Yayınevi.

Brown, T. (2008). Design thinking. Harvard Business Review (6), 84.

Curedale, R. A. (2013). Design Thinking: process and methods manual (Design methods series). Topanga, California Design Community College Inc.

Drucker, P. (1985). The Discipline of Innovation. Harvard Business Review, 63(3), 67-72.

Ergen, M. (2014). Girişimci kapital: silikon vadisi tarihi ve startup ekonomisi: Koç Üniv. Yayinlari.

Gilbert, C., \& Eyring, M. (2015). Beating the ODDs when you launch a new venture. IEEE Engineering Management Review, 43(1), 22-27. 
Soyupak \& Bagli / International Journal of Research in Business and Social Science,

Vol 8 No 4, 2019 ISSN: 2147-4486

Glen, R., Suciu, C., C., \& Anson, R. (2015). Teaching Design Thinking in Business Schools. The International Journal of Management Education, 13, 182-192.

Hoffman, R., \& Casnocha, B. (2012). The start-up of you. New York, NY: Crown Business.

Johansson-Sköldberg, U., Woodilla, J., \& Çetinkaya, M. (2013). Design Thinking: Past, Present and Possible Futures. Creativity \& Innovation Management, 22(2), 121-146, doi:10.1111/caim.12023.

Kelley, T., \& Littman, J. (2005). The ten faces of innovation: IDEO's strategies for beating the devil's advocate \& driving creativity throughout your organization. New York, NY: Currency/Doubleday.

Kumar, V. (2013). 101 design methods : a structured approach for driving innovation in your organization. Hoboken, N.J.: Wiley.

Melles, G., Howard, Z., \& Thompson-Whiteside, S. (2012). Teaching Design Thinking: Expanding Horizons in Design Education. Procedia - Social and Behavioral Sciences, 31, 162-166, doi:10.1016/j.sbspro.2011.12.035.

Michalko, M. (2006). Thinkertoys : a handbook of creative-thinking techniques. Berkeley, Calif.: Ten Speed Press.

Müller, R. M., \& Thoring, K. (2012). Design thinking vs. lean startup: A comparison of two user-driven innovation strategies.

Osgood, C.E., Suci, G., \& Tannenbaum, P. (1957). The measurement of meaning. Urbana, IL: University of Illinois Press.

Sabuncu, B. (2014). KOBl'lerde yenilik ve engellerinin tespitine yönelik bir araştırma. Journal of Business Research, Vol 6. No 1. 103-123.

Tarekegne, W. M., \& Gelaneh, A. H. (2019). The Integration of Entrepreneurship Education in to Ethiopian Universities Formal Curriculum. International Journal of Research in Business and Social Science, 8(2), 61-73. https://doi.org/10.20525/ijrbs.v8i2.191

Tübitak (2017). Sermaye Destek Programı. https://www.tubitak.gov.tr/tr/destekler/sanayi/ulusal-destekprogramlari/icerik-1512-teknogirisim-sermaye-destegi-programi-bigg Accessed 27 January 2017. 